\title{
Obesity and related risk factors among low socio-economic status minority students in Chicago
}

\author{
Youfa Wang ${ }^{1, *}$, Huifang Liang ${ }^{2}$, Lisa Tussing ${ }^{2}$, Carol Braunschweig ${ }^{2}$, Benjamin Caballero' \\ and Brian Flay $^{3}$ \\ ${ }^{1}$ Center for Human Nutrition, Department of International Health, Bloomberg School of Public Health, Johns Hopkins \\ University, 615 North Wolfe Street, Baltimore, MD 21205, USA: ${ }^{2}$ Department of Human Nutrition, University of \\ Illinois at Chicago, USA: ${ }^{3}$ College of Health and Human Sciences, Oregon State University, USA
}

Submitted 1 May 2006: Accepted 17 November 2006: First published online 19 February 2007

\begin{abstract}
Objectives: To assess overweight and related risk factors among urban low socioeconomic status (SES) African-American adolescents in an attempt to study the underlying causes of ethnicity and gender disparities in overweight.

Methods: Cross-sectional data collected on anthropometric measures, diet, physical activity and family characteristics from 498 students in grades 5-7 in four Chicago public schools were analysed to study the risk factors for overweight using stepwise regression analysis.

Results: Only 37.2\% of the students lived with two parents. Nearly $90 \%$ had a television (TV) in their bedroom, and had cable TV and a video game system at home. Overall. 21.8\% (17.7\% boys versus $25.1 \%$ girls) were overweight (body mass index (BMI) $\geq 95$ th percentile); and $39.8 \%$ had a BMI $\geq 85$ th percentile. Compared with national recommendations, they had inadequate physical activity and less than desirable eating patterns. Only 66.1\% reported having at least 20 min vigorous exercise or $30 \mathrm{~min}$ of light exercise in $\geq 5$ days over the past 7 days; $62.1 \%$ spent $>3 \mathrm{~h}$ days $^{-1}$ watching TV/playing video games/computer, while $33.1 \%$ spent $\geq 5 \mathrm{~h}$ days $^{-1}$. Their vegetable and fruit consumption was low, and they consumed too many fried foods and soft drinks: $55.1 \%$ consumed fried food twice or more daily and $19.5 \%$ four times or more daily; $70.3 \%$ consumed soft drinks twice or more daily and $22.0 \%$ four times or more daily on average. Gender, physical activity and pocket money were significant predictors of overweight $(P<0.05)$

Conclusions: Several factors in the students' behaviours, school and family environments may increase overweight risk among this population. There is a great need for health promotion programmes with a focus on healthy weight and lifestyle, and targeting urban low-SES minority communities.
\end{abstract}

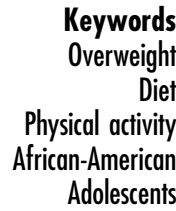

The dramatic increase in obesity in the USA and worldwide over the past two decades is believed to be a consequence of social-environmental factors that favour a positive energy balance resulting from increased energy intake and inadequate physical activity $(\mathrm{PA})^{1-4}$. Prevention of obesity in children and adolescents is a public health priority due to the critical periods for the development of obesity, the many long-term consequences of childhood obesity and the difficulty of maintaining weight loss in adults ${ }^{5-9}$.

Currently, approximately one-third of American children and adolescents are overweight or obese ${ }^{10}$. Low socio-economic status (SES) and minority groups are disproportionately affected ${ }^{4,10,11}$. The US 1999-2004 National Health and Nutrition Examination Survey (NHANES) data revealed considerable differences in the prevalence of overweight across ethnic groups, in particular in older children and adolescents, although the ethnic differences became smaller by 2004, which might be due to the possible influence of sample selection as well as a faster increase in the prevalence among nonHispanic white than in minority groups between 1999 and $2004^{10}$. In 1999-2000, non-Hispanic black (40.4\% body mass index (BMI) $\geq 85$ th percentile) and MexicanAmerican (43.8\%) adolescents aged $12-19$ years were at a much higher risk than their non-Hispanic white counterparts (26.5\%). Africa-American (AA) adolescents' risk of being overweight (BMI $\geq 95$ th percentile 23.6\%) was double that of whites (12.7\%). The ethnic disparity in obesity in the USA is probably due to a number of complex factors, among which SES factors and differences in people's eating and PA patterns are likely to be the key 
contributors. However, to our knowledge, limited indepth data are available to explain the underlying causes of the ethnic SES disparities.

Another interesting pattern indicated by the US 1999-2000 NHANES data is the large gender difference in the prevalence of overweight in AA children and adolescents. Further, the gender differences became greater with age ${ }^{10}$. For example, $45.5 \%$ of AA adolescent girls versus $35.7 \%$ of boys were at risk of overweight; for those actually overweight, the figures were 26.6 versus $20.7 \%$. In contrast, the gender difference was very small in whites (e.g. overweight: 25.4 versus 27.4\%) or MexicanAmericans (43.5 versus 44.2\%). It is unclear whether these are related to gender differences in eating and/or PA behaviours among AA adolescents.

Overweight among young people in the USA is continuing to increase, and the increase in prevalence is the highest among non-Hispanic black and MexicanAmerican adolescents. Research needs to focus on reasons for the increase and what interventions may help reduce the prevalence. Overweight is related to dietary intake and PA, both of which are influenced by social, economic and physical environments. It is speculated that low-SES minority children and adolescents are at the highest risk compared with other groups. Some researchers seem to support this speculation ${ }^{12}$, but others provide conflicting evidence $^{13,14}$. Recently Whitman and colleagues surveyed parents of 542 children aged 2-12 years in six Chicago community areas, of whom a large proportion were lowSES AAs. They reported that $58 \%$ of the children were at risk of overweight or were already overweight.

The purpose of the present study was to examine the prevalence of overweight and the related risk factors among urban low-SES AA adolescents. We explored whether our target population had a more serious obesity problem than the US general population and, if so, what factors were responsible for that increased risk of obesity.
The present study focused on family and individual factors such as eating and PA behaviours (the conceptual model is shown in Fig. 1). We also studied the associations between pocket money, risk of overweight and dietary intake patterns. Pocket money was selected as an indicator of parenting style and children's flexibility to purchase unhealthy snack foods. We hypothesised that compared with the general population as revealed by national survey data, the target group had certain individual and family characteristics that put them at increased risk of overeating and sedentary behaviours; and children who had more pocket money were more likely to consume unhealthy snack foods and were at higher risk of overweight. The baseline data collected in a school-based intervention study in Chicago were used. Our findings will help provide useful information to guide obesity intervention programmes among low-SES minority adolescents in urban areas.

\section{Materials and methods}

\section{Overview of study design}

Supported by the National Institute of Diabetes and Digestive and Kidney Diseases, in 2003 we initiated a 3year randomised intervention trial, a pilot study, to test the feasibility and effectiveness of a school-based, environmental obesity prevention programme in low-SES AA students. Four Chicago public schools were selected from low-SES AA communities and randomly assigned to the control and the intervention groups. The intervention focused on the school physical and social environment, and aimed at promoting healthy eating and PA. The study was named the HEALTH-KIDS ('Healthy Eating and Active Lifestyles from school To Home for KIDS') Study. $\bar{C}$ urrently we are in the follow-up and evaluation phase of the study. More details about the study design are provided elsewhere $^{15}$.

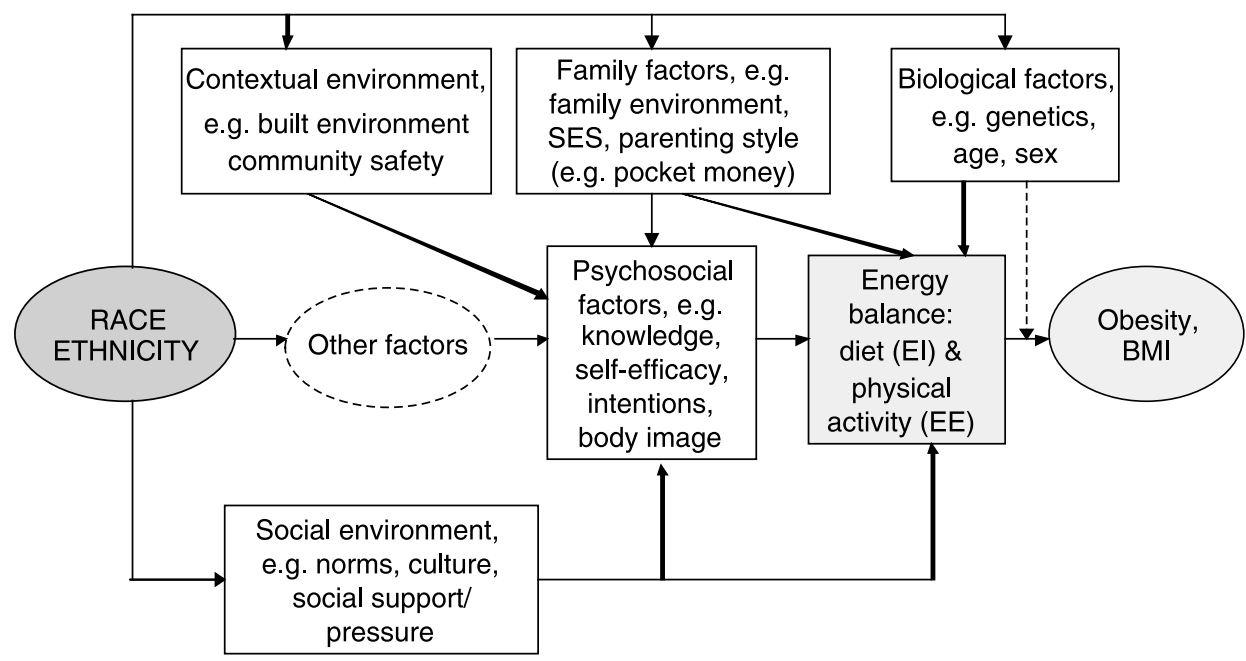

Fig. 1 Conceptual model: contributors of ethnic disparity in obesity. The present study focused on family and individual factors (diet and physical activity). BMI - body mass index; EI - energy intake; EE - energy expenditure; SES - socio-economic status 
Our school selection criteria included being located within the city of Chicago or nearby suburbs, $>80 \%$ of students were $\mathrm{AA},>70 \%$ of the students were from lowincome families, with grades 5-8 in the same building, and with a student body that was not highly mobile $(<30 \%)$. Thirteen schools fit the selection criteria when we initially proposed the study; however, several declined to participate when they learned more detailed requirements when the project was funded; and four finally were included based on their cooperation and our available resources. All students in grades 5-7 at baseline (autumn 2003) were recruited to participate in this study. At baseline, two rounds of data collection were conducted, one in spring 2003 and the other in autumn 2003. The spring survey served two goals, to test the study protocols and to collect preliminary data to allow for testing possible seasonal differences in student behaviours.

Thus, the 2003 spring and autumn surveys differed: (1) they were conducted in different seasons; (2) more students were enrolled in the autumn, 249 versus 424 students; (3) more detailed data were collected in the 2003 autumn full survey; and (4) in the autumn survey, parents who provided consent for themselves to participate actively in the study were surveyed, and 108 returned the surveys that were mailed to them. Note that our analysis shows that, in general, the prevalence of overweight and students' eating and PA patterns were similar in the spring and autumn data collection. The study was carried out following study protocols approved by the Institutional Review Board at the University of Illinois at Chicago and Johns Hopkins University Bloomberg School of Public Health.

\section{Subjects}

To use all the information we collected most efficiently, the present study was based on the pooled spring and autumn data (see Appendix). The spring data were used only for those students without autumn data $(n=79)$. Thus, the present study included 498 students, 218 (43.8\%) boys and $280(56.2 \%)$ girls. Overall the recruitment rate was $67 \%$ in the four schools. In spring 2003, a subsample $(50 \%, n=121)$ of the 249 students surveyed in spring 2003 finished an additional Health and Nutrition Questionnaire (HNQ) to provide information regarding their family characteristics, eating and PA. Approximately 170 students surveyed in the spring also participated in the autumn survey. The rest dropped out of the study, predominantly because of transferring to other schools in the new school year, which was a reflection of the approximately 30\% annual transfer rate for the participating schools. Analysis regarding children's anthropometric measures was conducted for 490 students who had complete data, while 458 students had sufficient data to allow for further analysis regarding their eating and PA patterns or other factors that might be related to obesity.

\section{Data collection and measures}

Data were collected at the individual and group levels from students, parents, school records, school personnel and local communities. Students' anthropometric measures were assessed through direct measurements conducted by trained interviewers in the schools. Other data were collected from students through self-administered questionnaire surveys carried out in small groups and assisted by interviewers when needed. The present study was primarily based on data collected from the students, but some information collected from their parents and schools were used as well.

\section{Physical examination}

Measures of students' weight, height, waist circumference, triceps skinfold thicknesses and blood pressure were collected. Height was measured to the nearest $0.1 \mathrm{~cm}$ using a portable stadiometer (Shorr Board Stadiometer and weight was assessed to the nearest $0.1 \mathrm{~kg}$ for each participant in light clothing without shoes using the Tanita BWB-800A electronic scale. We measured each student's triceps skinfold thickness in a private area using a Body Care Harpenden Skinfold Caliper HSK-BI; waist circumference was measured in the smallest area above the umbilical but below the last rib, using a flexible tape measure. Blood pressure was assessed using an Omron HEM-907 digital blood pressure monitor. Each measure was assessed twice in each participant. The means were used in our analysis.

\section{Sociodemographic and family characteristics}

These include students' age, gender, grade, race/ethnicity and family structure collected from the students. In addition, further information regarding parental education and family income were collected from parents, but only just over 100 of the parents returned the survey.

\section{Dietary intake}

Students' eating patterns were assessed through asking a number of dietary intake questions adapted from the YRBSS (Youth Risk Behavier Surveillance. System) and CATCH (Child and Adolescent Trial for Cardiovascular Health) study questionnaires. For example, the participants were asked, over the past 7 days, how often he/she ate fruit, vegetables, green salad, fried foods and soft drinks, as well as questions about their snack food eating patterns (e.g. whether they ate snacks between meals, when watching television (TV), on the way home from or to school and when doing homework). In addition, their habitual eating behaviours were assessed using a 152-item food-frequency questionnaire (FFQ) developed by Harvard University - the Youth and Adolescent Questionnaire $(Y A Q)^{16,17}$. In the present study, we focused on data from the dietary questions, but not the YAQ data. Our ongoing separate analysis of the YAQ data suggested an over- 
reporting problem among some students (Wang and $\mathrm{Li}$, 2006, unpublished).

\section{$P A$ and sedentary behaviours (also called inactivity)}

Students' PA and inactivity were assessed using a questionnaire we adapted from one used in the Girls Health Enrichment Multi-Site Studies (GEMS) ${ }^{18}$ with additional questions from the YRBSS questionnaire asking about children's overall PA and inactivity patterns. Changes were made to fit the needs of our study. Some examples of the overall PA questions include: 'On how many of the past 7 days, did you do at least 20 min of exercise hard enough to make you sweat and breathe hard?', 'On how many of the past 7 days did you do at least $30 \mathrm{~min}$ of light exercise that was NOT hard enough to make you sweat or breathe hard?', 'On an average school day, how many hours do you watch TV or videos, or play computer or video games?' Two additional questions were asked about the students' participation in physical education (PE) class, the frequency and how much time they actually spent exercising each time. In the present study, we focused on these overall PA questions.

In order to group the participants into different PA level groups, we generated a 'PA-MET (Metabolic Equivalent) score' for each participant by combining the information collected using the two PA questions regarding hard and light exercise. MET is a unit to measure intensity of a given PA using its estimated oxygen consumption per unit time ${ }^{19}$. We assigned an average MET value of 6 for vigorous (or 'hard') exercise and 3 for light exercise, and then calculated the summary MET scores as follows: (1) vigorous exercise MET score $=6 \times$ MET $\times$ frequency $\times 20 \mathrm{~min}$; (2) light exercise $\mathrm{MET}$ score $=3 \times$ MET $\times$ frequency $\times 30 \mathrm{~min}$; and (3) PA-MET score $=$ hard exercise MET score + light exercise MET score. The sex- and age-specific PA-MET score median was used to group the participants into the high-PA and low-PA groups.

\section{Other information}

We collected additional health-related information from the students, including sexual maturation status, knowledge, attitudes, beliefs and self-efficacy, and cigarette smoking. In the parents/legal guardians survey, mothers or other primary caregivers were asked to provide information regarding family characteristics, family health history, family food environment (e.g. food preparation and available food at home), their own body weight status, eating and PA patterns, education and occupation, etc. At the school level, information regarding the school environment, policies and programmes was collected using the Centers for Disease Control and Prevention (CDC) School Health Index ${ }^{20}$.

\section{Classification of overweight}

BMI (weight $(\mathrm{kg}) /$ height $\left(\mathrm{m}^{2}\right)$ ) for each participant was calculated based on his/her weight and height. We used the 2000 CDC Growth Charts (i.e. the age-sex-specific BMI percentile) to define the outcome variables: (1) 'at risk of overweight', 85 th percentile $\leq$ BMI $<95$ th percentile; and (2) 'overweight', BMI $\geq 95$ th percentile ${ }^{21}$.

\section{Statistical analysis}

We first examined the prevalence of overweight and the participants' eating and PA patterns. Next, we tested the between-groups (gender, grades and schools) differences using chi-square tests at the 0.05 significance level. Finally, with logistic regression analysis, we studied the associations between overweight and the potential risk factors including students' sociodemographic and family characteristics and their eating and PA patterns. We conducted stepwise regression analysis with backward selection, using $P>0.05$ as the a priori criterion for removing variables. The following variables were included in our full model: age, gender, family structure, number of siblings, type of housing, family car ownership, pocket money, eating behaviours, PA, TV viewing, as well as the means used to get to school. Some of the sociodemographic variables were included in the full model following a common practice to include them as covariate. In addition, we believed that there were measurement errors in the diet and PA variables as indicators of the participants' habitual eating and PA behaviours. Thus, these sociodemographic variables might help capture some of the unmeasured effects of diet and PA. Moreover, some sociodemographic variables could be potential confounders when the influence of diet and PA on obesity is studied. Age and gender were forced to be included in the models. Further, we tested effect modification through testing related interaction terms (between age and sex and some other variables) and conducting stratified analysis based on biological considerations and previous findings in the literature. Data management and data analysis were performed with SAS Version 8.2.

\section{Results}

\section{Study participants' sociodemographic and family characteristics}

The participants' characteristics are provided in Table 1. Their mean age was 11.9 (standard deviation (SD) 1.0); $56.2 \%$ were girls; about one-third were in grades 5, 6 and 7, respectively; and 98.8\% were AA. Approximately half (47.9\%) lived in single-parent families; only one-third (37.2\%) lived with two parents; and 14.9\% lived with grandparents, foster parents or other relatives. All had a TV at home, nearly $90 \%$ had a TV in his/her bedroom, and had cable TV and a video game system, and 75\% had a computer at home. Over two-thirds of these students received $\geq$ US $\$ 1$ pocket money on average each day, while $37.5 \%$ received $>$ US $\$ 2$. The majority (89.3\%) of their families owned a car, and $61.6 \%$ owned a house or apartment. 
Table 1 Study participants' sociodemographic and family characteristics $(n=498)^{\star}$

\begin{tabular}{lccr}
\hline Characteristic & $\begin{array}{c}\text { Proportion } \\
(\%)\end{array}$ & Characteristic & $\begin{array}{c}\text { Proportion } \\
(\%)\end{array}$ \\
\hline Girls & 56.2 & TV/video game/computer & \\
African-American & 98.8 & Family owned a TV & 100.0 \\
Grade & & Had TV in the child's bedroom & 85.3 \\
5th & 35.3 & Had cable TV at home & 88.6 \\
6th & 36.6 & Had video game at home & 88.8 \\
$\quad$ 7th & 28.1 & Had computer at home & 74.4 \\
Family structure (the child lived with) & 37.2 & Daily pocket money & 16.1 \\
$\quad$ Two parents & 47.9 & None & 15.6 \\
$\quad$ Single parent & 8.1 & US $\$ 1-2$ & 30.8 \\
$\quad$ Grandparents only & 6.8 & $>$ US $\$ 2$ & 37.5 \\
$\quad$ Foster parents, relatives, or others & & & \\
\hline
\end{tabular}

* Based on the pooled data.

Additional family information was provided by 108 mothers or other primary care providers. We tested if the students whose parents returned the parents/legal guardians survey were different from those whose parents did not. There were no significant differences in their BMI, PA, TV viewing hours, pocket money, snacking habit or eating patterns between the two groups $(P>0.05)$. The parental survey data confirmed our participants' low-SES status: $29.8 \%$ of the households had a family income $<$ US\$10000, 59.6\% < US\$30000, and only 13.5\% had $>$ US\$40000; 38.0\% of the household heads had high school education or less; $50.9 \%$ were enrolled in the federal Food Stamp Program and 32.7\% in some other public assistance programmes; almost half (43.5\%) of the mothers or other primary caregivers were unemployed. Over one-third (36.1\%) reported never or rarely having fresh fruits at home. Only $17.6 \%$ had vegetables served with dinner. When asked 'How many times did you exercise with your child in the last month?', 56.1\% answered never, while only $10.3 \%$ did so four or more times.

Interestingly, we found that only $12.2 \%$ of the parents/legal guardians considered their neighbourhood unsafe, which was corroborated by the high proportion of students reported walking to school (62\%). This finding contrasted with the widely held belief that public safety is a major barrier for low-SES minority children to have adequate PA after school. The majority (95.3\%) reported that they monitored their children's TV, computer or video game use; and 46.5\% reported always doing so. However, as shown by data presented below, two-thirds of the students reported spending $\geq 3 \mathrm{~h}$ days $^{-1}$ on these activities.

\section{Prevalence of at risk of overweight and overweight} We estimated the prevalence of overweight $(\geq 95$ th percentile) and combined prevalence of at risk of overweight and overweight ( $\geq 85$ th percentile) based on the spring, autumn and pooled data. The prevalence estimate based on the pooled data (Table 2) was slightly lower that that based on the separate spring or autumn data (not presented), but the differences were small and not statistically significant. Approximately $40 \%$ of the participants were at risk of overweight and 22\% were overweight. Table 2 shows the prevalence by gender, age, PA and average daily pocket money based on the pooled data. Overall, 39.8\% (95\% confidence interval (CI) 35.4-44.3\%) of the participants (39.5\% in boys versus $40.0 \%$ in girls) had a BMI above the 85 th percentile. Although the combined prevalence was similar in boys and girls, more girls were overweight than boys (25.1\% (95\% CI 20.0-30.6\%) versus 17.7\% (95\% CI 12.8-23.4\%), $P<0.05$ ). There were no meaningful differences in the prevalence by age or across grades or schools. Students who reported being engaged in more exercise had a lower prevalence of overweight (16.9 versus $26.4 \%, P<0.05$ ). There was a 'U'-shaped association between daily TV/video/computer time and overweight. Students whose reported TV/video/computer time was 2$3 \mathrm{~h}$ had the lowest combined prevalence $(P<0.05)$. Students who reported receiving more pocket money ( $\geq$ US\$2) had a lower prevalence of overweight (15.9 versus $25.2 \%, P<0.05$ ), but the combined prevalence was similar (37.2 versus $41.5 \%, P>0.05)$.

\section{Participants' eating and physical activity patterns}

As indicated in Tables 3 and 4, a number of behavioural patterns might have put the target population at risk of overweight. Compared with related national guidelines and recommendations, the students had inadequate PA and less than desirable eating patterns. American children and adolescents are recommended to have at least 3050 min of moderate to vigorous exercise each day on most days each week ${ }^{22}$. Our data show that the students' exercise participation rate was low (Table 4). Two-thirds (66.1\%) reported having at least $20 \mathrm{~min}$ vigorous exercise or $30 \mathrm{~min}$ of light exercise on $\geq 5$ days over the past week. However, only approximately one-third had at least 20 min hard exercise on $\geq 5$ days over the past week. Almost two-thirds (62.1\%) spent $\geq 3$ h each day watching TV or playing video games, or using a computer, while 
Table 2 Prevalence of at risk of overweight and overweight (\%) by characteristics*

\begin{tabular}{|c|c|c|c|c|}
\hline Groups & $\begin{array}{l}\text { Combined prevalence } \\
\text { (BMI } \geq 85 \text { th percentile) }\end{array}$ & $\begin{array}{c}\text { At risk of overweight } \\
(85 \text { th } \leq \text { BMI } \\
<95 \text { th percentile) }\end{array}$ & $\begin{array}{c}\text { Overweight } \\
\text { (BMI } \geq 95 \text { th percentile) }\end{array}$ & $\begin{array}{c}\text { Group-difference } \\
\text { in overweight, } P \text {-value }\end{array}$ \\
\hline Boys and girls & 39.8 & 18.0 & 21.8 & - \\
\hline \multicolumn{5}{|l|}{ Sex } \\
\hline Boys & 39.5 & 21.8 & 17.7 & \multirow{2}{*}{$0.049 \ddagger$} \\
\hline Girls & 40.0 & 14.9 & 25.1 & \\
\hline \multicolumn{5}{|l|}{ Age (years) } \\
\hline $10+$ & 41.7 & 19.5 & 22.2 & \multirow[t]{4}{*}{0.820} \\
\hline $11+$ & 36.9 & 16.1 & 20.8 & \\
\hline $12+$ & 42.1 & 18.0 & 24.1 & \\
\hline $13+$ & 39.1 & 20.3 & 18.8 & \\
\hline \multicolumn{5}{|c|}{ Physical activity $\dagger$} \\
\hline Low & 41.4 & 15.0 & 26.4 & \multirow[t]{2}{*}{$0.015 \ddagger$} \\
\hline High & 38.7 & 21.8 & 16.9 & \\
\hline \multicolumn{5}{|c|}{ Daily TV/video game/computer time } \\
\hline$\leq 1 \mathrm{~h}$ & 44.6 & 17.4 & 27.2 & \multirow[t]{3}{*}{0.220} \\
\hline $2-3 h$ & 30.6 & 12.9 & 17.7 & \\
\hline$\geq 4 \mathrm{~h}$ & 44.5 & 23.1 & 21.5 & \\
\hline \multicolumn{5}{|c|}{ Daily pocket money } \\
\hline$\leq$ US\$2 & 41.5 & 16.3 & 25.2 & \multirow[t]{2}{*}{$0.021 \ddagger$} \\
\hline$>$ US\$2 & 37.2 & 21.3 & 15.9 & \\
\hline
\end{tabular}

BMI-body mass index.

${ }^{*}$ Based on the pooled data. At risk of overweight and overweight were defined based on BMI percentiles ${ }^{21}$. †Based on median of MET (metabolic equivalent) values.

$\ddagger P<0.05$.

one-third (33.1\%) reported spending $>5$ h each day. Our data also showed that students did not use the PE class time well in terms of doing exercise as only $39.2 \%$ reported spending $30 \mathrm{~min}$ (approximately three-quarters of the PE time) doing exercise, while $>40 \%$ spent $<20 \mathrm{~min}$ (about half of the PE time). In general, boys tended to be more active than girls. For example, boys were more likely to have at least 20 min vigorous exercise on $\geq 5$ days than girls $(P<0.05)$ and exercise more than $30 \mathrm{~min}$ in $\mathrm{PE}$ class $(P<0.05)$ and to walk to school $(P<0.05)$, and less likely to spend $\geq 5 \mathrm{~h}$ per day watching TV or playing video games $(P<0.05)$.

Similarly to patterns shown by national data for US children and adolescents ${ }^{23}$, eating snack food was common in our participants. Our spring survey data (see Table 4) show that over one-fifth reported always or often eating snack between meals, on their way home from or to school, and when doing homework. Over 50\% reported always or often eating snack foods when watching TV. However, only a quarter (24.3\%) reported always or often choosing healthy food when snacking, and most students (57.1\%) reported disliking the taste of most healthy foods (Table 3 ).

The students' vegetable and fruit (V\&F) consumption was low, and they consumed too many fried foods and soft drinks (Table 4). When asked how often over the past 7 days they ate food in a certain food group, only half (53.4\%) reported eating fruits $\geq 2$ times a day, and $45.2 \%$ ate vegetables $\geq 2$ times a day; $55.1 \%$ consumed fried food $\geq 2$ times a day and $19.5 \%$ did so $\geq 4$ times a day; $70.3 \%$ consumed soft drinks $\geq 2$ times a day, and $22.0 \%$ did so $\geq 4$ times a day on average. The only significant gender difference was that girls consumed green salad more frequently than boys. It is possible that our sample size might not allow for detecting smaller gender differences.

\section{Predictors of overweight}

Our stepwise logistic regression analysis shows that gender, PA and pocket money were the significant predictors (Table 5). Girls were more likely to be overweight than boys (odds ratio $(\mathrm{OR})=2.02$ ); a high PA level (classified based on the median) was associated with reduced risk $(\mathrm{OR}=0.59)$; and removing the variable of pocket money from the model did not change the association. Our findings that students who received more pocket money $(>\mathrm{US} \$ 2)$ were at lower risk $(\mathrm{OR}=0.56)$ was unexpected, as we had suspected that they might be more likely to eat snack foods, and thus might be more likely to be overweight. Our analysis did show that compared with children who had less snack money ( $\leq$ US\$2), children who had > US\$2 were more likely to eat fried food and consume soft drinks and snack food, but they were also more likely to eat more V\&F (see Table 6). Our further analysis using the FFQ data shows that they had higher energy intake (by $769 \mathrm{kcal}$ in boys and $453 \mathrm{kcal}$ in girls) and ate more snack food (by 2.7 servings in boys and 1.2 in girls) controlling for age and BMI. All these differences were significant $(P<0.05)$.

We conducted further analyses seeking to explain the negative association between pocket money and overweight. We found that children who had $\geq$ US\$2 snack money were more likely to have more exercise than their counterparts (Table 6). There were no significant differences between the two groups regarding their family structure, type of housing, family income or their primary 
Table 3 The study participants' physical activity and snacking patterns (\%)

\begin{tabular}{|c|c|c|c|c|}
\hline Variables & All $(n=458)$ & Boys $(n=198)$ & Girls $(n=260)$ & $\begin{array}{c}\text { Gender } \\
\text { difference, } P \text {-value }\end{array}$ \\
\hline \multicolumn{5}{|c|}{ Physical activity } \\
\hline \multicolumn{5}{|c|}{ Had at least 20 min of hard exercise in the past 7 days } \\
\hline None & 10.3 & 7.6 & 12.4 & \multirow[t]{4}{*}{0.069} \\
\hline $1-2$ days & 28.1 & 24.7 & 30.6 & \\
\hline $3-4$ days & 25.4 & 25.8 & 25.2 & \\
\hline$\geq 5$ days & 36.2 & 41.9 & 31.8 & \\
\hline \multicolumn{5}{|c|}{ Had at least $30 \mathrm{~min}$ of light exercise in the past 7 days } \\
\hline None & 18.5 & 17.8 & 19.1 & \multirow[t]{4}{*}{0.652} \\
\hline $1-2$ days & 34.7 & 37.8 & 32.3 & \\
\hline $3-4$ days & 23.6 & 21.4 & 25.3 & \\
\hline$\geq 5$ days & 23.2 & 23.0 & 23.3 & \\
\hline \multicolumn{5}{|c|}{ Daily TV/video games/computer time } \\
\hline$<3 \mathrm{~h}$ & 37.9 & 43.2 & 34.0 & \multirow[t]{3}{*}{$0.052^{*}$} \\
\hline $3-4 \mathrm{~h}$ & 29.0 & 29.4 & 28.6 & \\
\hline$\geq 5 \mathrm{~h}$ & 33.1 & 27.4 & 37.4 & \\
\hline \multicolumn{5}{|c|}{ Exercise time in PE class each time } \\
\hline$<10 \min$ & 13.8 & 14.7 & 13.1 & \multirow[t]{4}{*}{0.067} \\
\hline $10-20 \mathrm{~min}$ & 28.3 & 22.3 & 32.8 & \\
\hline $20-30 \mathrm{~min}$ & 18.6 & 18.3 & 18.9 & \\
\hline$>30 \mathrm{~min}$ & 39.3 & 44.7 & 35.2 & \\
\hline \multicolumn{5}{|l|}{ How to get to school } \\
\hline Walk & 65.8 & 71.1 & 61.8 & $0.038^{*}$ \\
\hline Bus & 10.8 & 7.1 & 13.5 & $0.029^{*}$ \\
\hline Drop off & 30.9 & 26.9 & 34.0 & 0.106 \\
\hline Bicycle & 0.7 & 1.0 & 0.4 & 0.410 \\
\hline \multicolumn{5}{|c|}{ Snacking } \\
\hline \multicolumn{5}{|c|}{ Choose healthy food when snacking } \\
\hline Never & 10.8 & 13.2 & 8.9 & \multirow[t]{4}{*}{0.118} \\
\hline Sometimes & 64.9 & 66.5 & 63.7 & \\
\hline Often & 16.4 & 15.2 & 17.4 & \\
\hline Always & 7.9 & 5.1 & 10.0 & \\
\hline \multicolumn{5}{|c|}{ Do not like the taste of most healthy foods } \\
\hline Very true & 19.1 & 18.6 & 19.5 & \multirow[t]{4}{*}{0.615} \\
\hline A little true & 38.0 & 35.0 & 40.2 & \\
\hline Not true & 34.1 & 36.2 & 32.5 & \\
\hline Cannot say & 8.8 & 10.2 & 7.8 & \\
\hline \multicolumn{5}{|c|}{ Only choosing familiar fruits } \\
\hline Very true & 39.6 & 46.4 & 34.3 & \multirow[t]{4}{*}{$0.016^{*}$} \\
\hline A little true & 37.6 & 34.6 & 39.9 & \\
\hline Not true & 15.0 & 10.1 & 18.9 & \\
\hline Cannot say & 7.8 & 8.9 & 6.9 & \\
\hline \multicolumn{5}{|l|}{ Snacking under stress } \\
\hline Never & 63.4 & 67.6 & 60.2 & \multirow[t]{3}{*}{0.052} \\
\hline Sometimes or often & 30.8 & 29.6 & 31.8 & \\
\hline Always & 5.8 & 2.8 & 8.0 & \\
\hline \multicolumn{5}{|c|}{ Snacking under depression } \\
\hline Never & 70.8 & 75.4 & 67.4 & \multirow[t]{3}{*}{0.192} \\
\hline Sometimes or often & 23.4 & 20.1 & 25.8 & \\
\hline Always & 5.8 & 4.5 & 6.8 & \\
\hline
\end{tabular}

${ }^{*} P<0.05$

caregivers' education (data not shown). Other possible explanations, such as differences in behaviours regarding pocket money by parents of overweight children, or reporting bias, could not be tested with our available data.

\section{Discussion}

With data collected from 498 students in grades 5-7 in four Chicago public schools located in low-SES AA communities, we found that $40 \%$ of the participants were at risk of overweight or overweight, while $22 \%$ were overweight. The prevalence was greater than the national average for all US adolescents, but was similar to that of AA adolescents ${ }^{10}$. Our findings were similar to those in our previous smaller survey of younger students (grades 3-6) in two different Chicago public schools $(42 \%)^{24}$, and in New York City public schools (43\% in kindergarten to 5 th grade $)^{25}$. Our reported prevalence is much lower than that reported by Whitman et al. ${ }^{12}$ for Chicago children which included younger children (2-12 years old).

Our data do not support the hypothesis that low-SES AA students are at higher risk of overweight than their higher SES counterparts based on national data, i.e. they had similar prevalence of at risk of overweight and 
Table 4 The study participants' eating patterns

\begin{tabular}{|c|c|c|c|c|}
\hline Variables & $\begin{array}{c}\text { All } \\
(n=121)\end{array}$ & $\begin{array}{l}\text { Boys } \\
(n=47)\end{array}$ & $\begin{array}{c}\text { Girls } \\
(n=74)\end{array}$ & $\begin{array}{l}\text { Gender difference, } \\
P \text {-value }\end{array}$ \\
\hline \multicolumn{5}{|c|}{$\begin{array}{l}\text { Eating patterns (how often consumed a certain food group over } \\
\text { the past } 7 \text { days) }\end{array}$} \\
\hline \multicolumn{5}{|c|}{ Fruits } \\
\hline Did not eat & 12.1 & 13.4 & 11.3 & 0.995 \\
\hline$<1$ time day $^{-1}$ & 12.9 & 13.3 & 12.7 & \\
\hline 1 time $^{\text {day }^{-1}}$ & 21.6 & 20.0 & 22.5 & \\
\hline $2-3$ times day ${ }^{-1}$ & 40.5 & 40.0 & 40.8 & \\
\hline$\geq 4$ times day $^{-1}$ & 12.9 & 13.3 & 12.7 & \\
\hline \multicolumn{5}{|l|}{ Vegetables } \\
\hline$\leq 1$ time day ${ }^{-1}$ & 54.8 & 67.4 & 47.2 & 0.103 \\
\hline $2-3$ times day $^{-1}$ & 37.4 & 27.9 & 43.1 & \\
\hline$\geq 4$ times day $^{-1}$ & 7.8 & 4.7 & 9.7 & \\
\hline \multicolumn{5}{|l|}{ Green salad } \\
\hline Did not eat & 48.3 & 54.6 & 44.4 & $0.030^{*}$ \\
\hline$<1$ time day $^{-1}$ & 15.5 & 20.4 & 12.5 & \\
\hline 1 time day $^{-1}$ & 19.8 & 22.7 & 18.1 & \\
\hline $2-3$ times day $^{-1}$ & 11.2 & 2.3 & 16.7 & \\
\hline$\geq 4$ times day $^{-1}$ & 5.2 & 0.0 & 8.3 & \\
\hline \multicolumn{5}{|l|}{ Fried food } \\
\hline Did not eat & 2.5 & 0.0 & 4.1 & 0.600 \\
\hline$<1$ time day ${ }^{-1}$ & 11.0 & 11.4 & 10.8 & \\
\hline 1 time ayy $^{-1}$ & 31.4 & 27.3 & 33.8 & \\
\hline $2-3$ times day ${ }^{-1}$ & 35.6 & 40.9 & 32.4 & \\
\hline$\geq 4$ times day $^{-1}$ & 19.5 & 20.4 & 18.9 & \\
\hline \multicolumn{5}{|l|}{ Soft drinks } \\
\hline Did not drink & 9.3 & 6.8 & 10.8 & 0.902 \\
\hline$<1$ time day ${ }^{-1}$ & 7.7 & 9.1 & 6.8 & \\
\hline 1 time day ${ }^{-1}$ & 12.7 & 11.4 & 13.5 & \\
\hline $2-3$ times day $^{-1}$ & 48.3 & 47.7 & 48.6 & \\
\hline$\geq 4$ times day $^{-1}$ & 22.0 & 25.0 & 20.3 & \\
\hline \multicolumn{5}{|l|}{ Snacking } \\
\hline \multicolumn{5}{|c|}{ Ate snack when watching TV } \\
\hline Never & 10.0 & 13.0 & 8.1 & 0.618 \\
\hline Sometimes & 39.2 & 34.8 & 41.9 & \\
\hline Often & 20.0 & 23.9 & 17.6 & \\
\hline Always & 30.8 & 28.3 & 32.4 & \\
\hline \multicolumn{5}{|c|}{ Ate snack between meals } \\
\hline Never & 44.6 & 41.3 & 46.6 & 0.783 \\
\hline Sometimes & 33.6 & 37.0 & 31.5 & \\
\hline Often & 10.9 & 13.0 & 9.6 & \\
\hline Always & 10.9 & 8.7 & 12.3 & \\
\hline \multicolumn{5}{|c|}{ Ate snack on way home or to school } \\
\hline Never & 28.3 & 30.4 & 27.0 & 0.606 \\
\hline Sometimes & 47.5 & 45.7 & 48.6 & \\
\hline Often & 12.5 & 8.7 & 14.9 & \\
\hline Always & 11.7 & 15.2 & 9.5 & \\
\hline \multicolumn{5}{|c|}{ Ate snack when doing homework } \\
\hline Never & 14.9 & 17.0 & 13.5 & 0.866 \\
\hline Sometimes & 63.7 & 59.6 & 66.2 & \\
\hline Often & 10.7 & 12.8 & 9.5 & \\
\hline Always & 10.7 & 10.6 & 10.8 & \\
\hline
\end{tabular}

Based on baseline data collected in spring 2003. ${ }^{*} P<0.05$.

Table 5 Significant predictors of overweight (BMI $\geq 95$ th percentile)

\begin{tabular}{lc}
\hline Variables & Odds ratio $(95 \% \mathrm{Cl})$ \\
\hline Gender (female versus male) & $2.02(1.23-3.30)$ \\
Physical activity (high versus low) & $0.59(0.37-0.95)$ \\
Pocket money (> US\$2 versus $\leq$ US\$2) & $0.56(0.34-0.94)$ \\
\hline
\end{tabular}

$\mathrm{BMI}$ - Body mass index; $\mathrm{Cl}$ - confidence interval.

Age was adjusted for in the logistic regression analysis. overweight $^{10}$. This is consistent with findings recently reported by Gordon-Larsen et al. ${ }^{13}$ and our findings based on the 1999-2002 NHANES data ${ }^{14}$. Using data collected from 13113 US adolescents in the Add Health Study, Gordon-Larsen et al.'s simulation analysis indicates that keeping adolescents in their same environments and changing only family income and parental education had a limited effect on the disparities in overweight. The prevalence of overweight remained elevated and even increased among higher SES AA females, although overweight prevalence decreased with increasing SES among white females. Among males, race disparity was lowest at the average SES level. They argued that one cannot automatically assume that the benefits of increased SES found among whites will transfer to other gender-ageethnic groups. Their findings and ours suggest that efforts to reduce ethnic disparities in obesity must target other factors, including environmental, social and cultural factors, besides income and education. Culturally appropriate programmes are needed to address the obesity problems faced by minority groups.

The higher prevalence of overweight in the low-SES AA Chicago students in our study compared with the national average is probably due to a number of complex social, behavioural, cultural and environmental factors. Our study suggests that family environment, eating behaviours, PA patterns and body image are all likely factors associated with increased risk. We found that a large proportion of the participants lived in single-parent families (47.9\%) and only one-third (37.2\%) lived with both parents. Nearly $90 \%$ had a TV in their bedroom; approximately $90 \%$ of the participating families had cable TV, a video game system and a computer. Such a family environment is likely to facilitate students' sedentary behaviours at home. Secondly, compared with the national recommendations, our participants did not have adequate PA, and they spent too much time watching TV or videos, or playing video games. National guidelines recommend that children and adolescents should engage in at least 60 min of daily PA, and at least 30-50 min of moderate to vigorous exercise on at least 3-5 days per week. One-third of the students reported spending $5 \mathrm{~h}$ or more watching $\mathrm{TV}$, video or playing video games daily.

In addition, more effort should be made to help these students to use their PE class time more effectively in doing exercise, because only 39.2\% reported spending $30 \mathrm{~min}$ (approximately three-quarters of the $\mathrm{PE}$ time) doing exercise and $>40 \%$ spent $<20$ min (half of the PE time). Illinois is the only state in the USA that requires daily PE. However, the guideline is not enforced vigorously, and schools can request exception. To our knowledge, the vast majority of Chicago public schools could only provide weekly PE, and there is no assurance of a high level of exercise. In most schools, there is only one PE teacher. Changes need be made to help improve PE and increase students' PA. 
Table 6 Differences in the participants' physical activity, eating and snacking patterns by amount of pocket money (\%)

\begin{tabular}{|c|c|c|c|c|}
\hline & $\begin{array}{c}\text { Pocket } \\
\text { money }>\text { US\$2 }\end{array}$ & $\begin{array}{c}\text { Pocket } \\
\text { money } \leq \text { US } \$ 2\end{array}$ & Test of difference, $P$-value & OR $(95 \% \mathrm{Cl})^{*}$ \\
\hline \multicolumn{5}{|l|}{ Eating pattern } \\
\hline Vegetables $\geq 3$ times day ${ }^{-1}$ & 32.5 & 16.4 & 0.060 & $2.84(1.08-7.45)$ \\
\hline Fruits $\geq 3$ times day ${ }^{-1}$ & 47.5 & 21.6 & $0.006 \dagger$ & $3.14(1.35-7.27)$ \\
\hline Fried food $\geq 3$ times day ${ }^{-1}$ & 47.6 & 24.3 & $0.014 \dagger$ & $3.04(1.32-6.99)$ \\
\hline Soft drinks $\geq 3$ times day ${ }^{-1}$ & 57.1 & 29.7 & $0.006 \dagger$ & $2.77(1.29-5.95)$ \\
\hline \multicolumn{5}{|l|}{ Snacking } \\
\hline Often or always ate snack between meals & 32.6 & 16.0 & 0.063 & $2.20(0.92-5.28)$ \\
\hline Often or always ate snack when watching TV & 65.1 & 42.7 & $0.022 \dagger$ & $2.62(1.19-5.76)$ \\
\hline Often or always ate snack when doing homework & 34.9 & 13.3 & $0.009+$ & $3.26(1.32-8.04)$ \\
\hline \multicolumn{5}{|l|}{ Physical activity } \\
\hline High level of physical activity $\ddagger$ & 57.5 & 46.6 & $0.032 \dagger$ & $1.54(1.04-2.26)$ \\
\hline Frequent exercise§ & 71.8 & 62.7 & 0.052 & $1.49(0.99-2.26)$ \\
\hline$P E$ exercise time $\geq 30 \mathrm{~min}$ & 46.2 & 34.9 & $0.022 \dagger$ & $1.68(1.13-2.48)$ \\
\hline TV viewing time $\geq 5 \mathrm{~h}$ aay $^{-1}$ & 37.9 & 29.9 & 0.098 & $1.40(0.93-2.09)$ \\
\hline
\end{tabular}

OR - odds ratio; $\mathrm{Cl}$ - confidence interval; PE - physical education.

${ }^{*}$ Cochran-Mantel-Haenszel test, controlled for age and sex.

$\dagger P<0.05$.

$\ddagger$ Based on MET (metabolic equivalent) median.

$\S$ Over the past 7 days, had at least 20 min hard or 30 min light exercise in $\geq 5$ days.

Our survey also highlighted a number of problem areas in students' eating behaviours. The participants' V\&F consumption was low. Only half (53.4\%) reported eating fruits twice or more daily over the past 7 days; for vegetables, the figure was $45.2 \%$. Only a small proportion of the participants met the national dietary guidelines of consuming at least five servings of V\&F. A large number of previous studies have addressed this problem in American children and adolescents, and ways to help increase their V\&F consumption ${ }^{26,27}$.

Of concern is the very high consumption of fried food and soft drinks found on our study. One-fifth of the students reported on average eating fried food or soft drinks four or more times each day. Energy-dense, nutrient-poor foods and snacks are increasingly consumed by adolescents, and this phenomenon has been linked to higher energy intakes and inadequate intake of certain micronutrients in this age group, which may increase the risk of developing obesity or other chronic diseases such as cancer and cardiovascular disease ${ }^{28-31}$. Energy intake was found to be positively associated with consumption of non-diet soft drinks. Harnack et al. ${ }^{32}$ reported that the mean adjusted daily energy intake was $1830 \mathrm{kcal}$ for schoolchildren who were non-consumers of soft drinks compared with $2018 \mathrm{kcal}$ for those who consumed $9 \mathrm{oz}$ of soda or more per day. In a 1.5-year follow-up study among 548 ethnically diverse schoolchildren, Ludwig et $a l^{33}$ reported that for each additional serving of soft drink consumed, children's risk of developing overweight increased by $60 \%$ (OR $=1.6$, 95\% CI 1.14-2.24) after controlling for potential confounders. Most recently, the American Academy of Pediatrics Committee on School Health concluded that the potential health problems associated with high intake of sweetened drinks include: (1) increased risk of developing overweight or obesity attributable to additional calories in the diet; (2) displacement of milk consumption, resulting in calcium deficiency with an attendant risk of osteoporosis and fractures; and (3) dental caries and potential enamel erosion $^{34}$. Therefore, great effort should be made to reduce consumption of fried food and soft drinks in lowSES minority students.

Consistent with findings based on national data ${ }^{23}$, snacking was common in this group. Over one-fifth reported often or always eating snack food between meals, on their way to school or going home, or when doing homework. Over one-half often or always ate snacks when watching TV. On the other hand, less than a quarter (24.3\%) reported often or always chosing healthy food when snacking. Additionally, we found that the majority of these children received some pocket money each day from their parents, and nearly 40\% received $>$ US $\$ 2$ each day. Based on data collected in three waves of nationally representative surveys between 1977 and 1996, Jahns et al. ${ }^{23}$ previously reported that for young people aged 2-18 years the prevalence of snacking had increased during this period. In the 1994-1996 data, 87\% of adolescents aged 12-18 years consumed some snack food, and snack food contributed $25 \%$ of their total energy intake. Our findings and the national data suggest an important area for future intervention efforts - to educate, empower and assist young people to select healthy snack foods.

National data collected in the 1999-2000 NHANES survey show that more AA girls than AA boys are at risk of overweight or overweight ( 45.5 versus $35.7 \%)^{10}$. Although we did not find such a gender difference in the combined prevalence in our participants (40.0\% in girls versus 39.5\% in boys), we found that the prevalence of overweight was higher in girls than in boys (25.1 versus $17.7 \%, P<0.05)$. The gender difference was probably due to some behavioural and biological differences between boys and girls. The YRBSS data show considerable gender 
differences in adolescents' eating and PA patterns ${ }^{26}$. Adolescent girls had less PA than boys. Similarly, our data show some gender differences in our participants' PA and eating patterns, which may help explain the gender difference in the prevalence of overweight. Boys took part in more vigorous exercise, watched less TV and were more likely to walk to school than girls.

Our finding of a reverse association between pocket money and overweight was unexpected. We suspected that students with more pocket money being less likely to be overweight might be due to: (1) they were of higher SES than their counterparts although they all were from the low-SES communities; or (2) they had higher levels of activity which made them feel hungry more frequently and thus requested more pocket money to purchase snack foods. On the other hand, we also thought that: (3) parents of overweight children might be more likely to limit their children's pocket money than other parents; or/and (4) other unknown factors. Our findings did not support (1), but seemed to support (2); and (3) and (4) might help explain our findings of a reverse association between the two. Our data did not allow us to test the latter two hypotheses. However, our data did show that these students consumed more snack foods, were more likely to consume fried food and soft drinks, and had higher energy intake. Further research based on longitudinal data is needed to understand fully the association between pocket money and overweight. We suggest that to provide children and adolescents with an appropriate amount of pocket money along with guidance and monitoring effort regarding how they use it should be part of an important parenting effort to help young people to form desirable living habits for promoting good health.

As well as the present study's strengths, it suffers from several limitations such as: (1) it was based on crosssectional data, thus causality cannot be tested; (2) the participants' eating and PA were assessed based on selfreported answers to survey questions, and this is likely to suffer from measurement error or even report bias; and (3) as it aimed to explore why low-SES AA adolescents have higher prevalence of overweight than the national average and to describe the target population's related characteristics, this study examined a relatively large number of variables. It is possible that some of the significant differences might be detected due to chance. Some researchers have argued that adjustment should be made (i.e. using smaller $P$-values) when making multiple comparisons $^{35}$, which we chose not to perform, but others disagree as to its importance and its use $\mathrm{e}^{36-38}$.

In conclusion, based on data collected from four Chicago public schools, we found that $40 \%$ of the students were at risk of overweight or were overweight. Our study identified several factors in these urban low-SES students' eating and PA patterns and in their school and family environments that may put them at increased risks of overweight. There is a great need for health promotion programmes with a focus on healthy weight and lifestyle, and targeting urban low-SES minority communities.

\section{Acknowledgements}

Sources of funding: The study was supported by the National Institute of Diabetes and Digestive and Kidney Diseases (\#1R01 DK63383).

Conflict of interest declaration: We declare no conflict of interest.

Authorship responsibilities: Y.W. was the principal investigator of the HEALTH-KIDS Study, designed and directed the present analysis, drafted and revised the manuscript, guided H.L. in conduction of data analysis, had full access to all of the data in the study, and took responsibility for the integrity of the data and the accuracy of the data analysis. C.B. assisted with study design and manuscript revision. B.C. assisted in manuscript revision. B.F. assisted during study design and manuscript revision. H.L. conducted data cleaning and analysis and assisted in data collection and manuscript revision. L.T. was the project coordinator, and assisted in subject recruitment, data collection and manuscript revision.

Acknowledgements: We are indebted to the participating schools, families and students in the study for their cooperation and support

\section{References}

1 World Health Organization (WHO). Obesity: Preventing and Managing the Global Epidemic. Report of a WHO consultation. WHO Technical Report Series 894. Geneva: World Health Organization, 2000.

2 French SA, Story M, Jeffery RW. Environmental influences on eating and physical activity. Annual Review of Public Health 2001; 22: 309-35.

3 Hill JO, Peters JC. Environmental contributions to the obesity epidemic. Science 1998; 280: 1371-4.

4 Wang Y, Monteiro C, Popkin BM. Trends of obesity and underweight in older children and adolescents in the United States, Brazil, China and Russia. American Journal of Clinical Nutrition 2002; 75: 971-7.

5 Bray GA, Bouchard C, James WPT. Handbook of Obesity. New York: Marcel Dekker, 1998.

6 Dietz WH. Critical periods in childhood for the development of obesity. American Journal of Clinical Nutrition 1994; 59: 955-9.

7 Must A, Strauss RS. Risks and consequences of childhood and adolescent obesity. Internationl Journal of Obesity 1999; 23: S2-11.

8 Power C, Lake JK, Cole TJ. Measurement and long-term health risks of child and adolescent fatness. International Journal of Obesity and Related Metabolic Disorders 1997; 21 : 507-26.

9 US Department of Health and Human Services, Public Health Service. The Surgeon General's Call To Action To Prevent and Decrease Overweight and Obesity. Rockville, MD: Office of the Surgeon General, 2001.

10 Ogden CL, Carroll MD, Curtin LR, McDowell MA, Tabak CJ, Flegal KM. Prevalence of overweight and obesity in the 
United States, 1999-2004. Journal of the American Medical Association 2006; 295: 1549-55.

11 Wang Y, Kumanyika S. Epidemiology of obesity in the United States. In: Kumanyika S, Brownson R, eds. Handbook of Obesity Prevention. Berlin: Springer, 2007; in press.

12 Whitman S, Williams C, Shah AM. Sinai Health System's Improving Community Health Survey: Report I. Chicago, IL: Sinai Health System, 2004.

13 Gordon-Larsen P, Adair LS, Popkin BM. The relationship of ethnicity, socioeconomic factors, and overweight in US adolescents. Obesity Research 2003; 11: 121-9.

14 Wang Y, Zhang Q. Are low-socioeconomic status American children and adolescents at increased risk of obesity? Trends in the association between overweight and family income between 1971 and 2002. American Journal of Clinical Nutrition 2006; 84: 707-16.

15 Wang Y, Tussing L, Odoms-Young A, Braunschweig C, Flay $\mathrm{B}$, Hedeker $\mathrm{D}$, et al. Obesity prevention among lowsocioeconomic status African American adolescents: the HEALTH-KIDS study. European Journal of Clinical Nutrition 2006; 60: 92-103.

16 Rockett HR, Breitenbach M, Frazier AL, Witschi J, Wolf AM, Field $\mathrm{AE}$, et al. Validation of a youth/adolescent food frequency questionnaire. Preventive Medicine 1997; 26: $808-16$.

17 Rockett HR, Wolf AM, Colditz GA. Development and reproducibility of a food frequency questionnaire to assess diets of older children and adolescents. Journal of the American Dietetic Association 1995; 95: 336-40.

18 Treuth MS, Sherwood NE, Butte NF, McClanahan B, Obarzanek E, Zhou A, et al. Validity and reliability of activity measures in African-American girls for GEMS. Medicine and Science in Sports and Exercise 2003; 35: 532-9.

19 Ainsworth BE, Haskell WL, Whitt MC, Irwin ML, Swartz AM, Strath SJ, et al. Compendium of physical activities: an update of activity codes and MET intensities. Medicine and Science in Sports and Exercise 2000; 32: S498-504.

20 Centers for Disease Control and Prevention (CDC). School Health Index (SHI) [online]. Available at http://apps.nccd. cdc.gov/shi/default.aspx. Accessed 12 November 2002.

21 Kuczmarski RJ, Ogden CL, Guo SS, Grummer-Strawn LM, Flegal KM, Mei Z, et al. CDC Growth Charts: United States. Advance data from vital and health statistics; no. 314. Hyattsville, MD: National Center for Health Statistics, 2000. Also available at www.cdc.gov/growthcharts

22 NIH Consensus Development Panel on Physical Activity and Cardiovascular Health. Physical activity and cardiovascular health. NIH Consensus Conference. Journal of the American Medical Association 1996; 276: 241-6.
23 Jahns L, Siega-Riz AM, Popkin BM. The increasing prevalence of snacking among US children from 1977 to 1996. Journal of Pediatrics 2001; 138: 493-8.

24 Braunschweig CL, Gomez S, Liang H, Tomey K, Doerfler B, Wang Y, et al. Obesity and risk factors for the metabolic syndrome among low-income, urban, African American schoolchildren: the rule rather than the exception? American Journal of Clinical Nutrition 2005; 81: 970-5.

25 Perez-Pena R. Obesity on the rise in New York public schools. New York Times, 9 July 2003.

26 Council on Sports Medicine and Fitness; Council on School Health. Active healthy living: prevention of childhood obesity through increased physical activity. Pediatrics 2006; 117: 1834-42.

27 Grunbaum JA, Kann L, Kinchen S, Ross J, Hawkins J, Lowry $\mathrm{R}$, et al. Youth risk behavior surveillance - United States, 2003. Morbidity and Mortality Weekly Report. Surveillance Summaries 2004; 53: 1-96.

28 Centers for Disease Control and Prevention (CDC) Guidelines for school health programs to promote lifelong healthy eating. Morbidity and Mortality Weekly Report. Recommendations and Reports 1996; 45: 1-41.

29 Mucci LA, Lindblad P, Steineck G, Adami HO. Dietary acrylamide and risk of renal cell cancer. International Journal of Cancer 2004; 109: 774-6.

30 Pelucchi C, Franceschi S, Levi F, Trichopoulos D, Bosetti C, Negri E, et al. Fried potatoes and human cancer. International Journal of Cancer 2003; 105: 558-60.

31 Brownell KD. Fast food and obesity in children. Pediatrics 2004; 113: 132.

32 Harnack L, Stang J, Story M. Soft drink consumption among US children and adolescents: nutritional consequences. Journal of the American Dietetic Association 1999; 99: 436-41.

33 Ludwig DS, Peterson KE, Gortmaker SL. Relation between consumption of sugar-sweetened drinks and childhood obesity: a prospective, observational analysis. Lancet 2001; 357: 505-8.

34 American Academy of Pediatrics Committee on School Health. Soft drinks in schools. Pediatrics 2004; 113: 152-4.

35 Bender R, Lange S. Adjusting for multiple testing - when and how? Journal of Clinical Epidemiology 2001; 54: 343-9.

36 Perneger TV. Adjusting for multiple testing in studies is less important than other concerns. British Medical Journal 1999; 318: 1288.

37 Rothman KJ. No adjustments are needed for multiple comparisons. Epidemiology 1990; 1: 43-6.

38 Greenland S, Robins JM. Empirical-Bayes adjustments for multiple comparisons are sometimes useful. Epidemiology 1991; 2: 244-51. 
Appendix: - Sample size: HEALTH-KIDS study baseline data

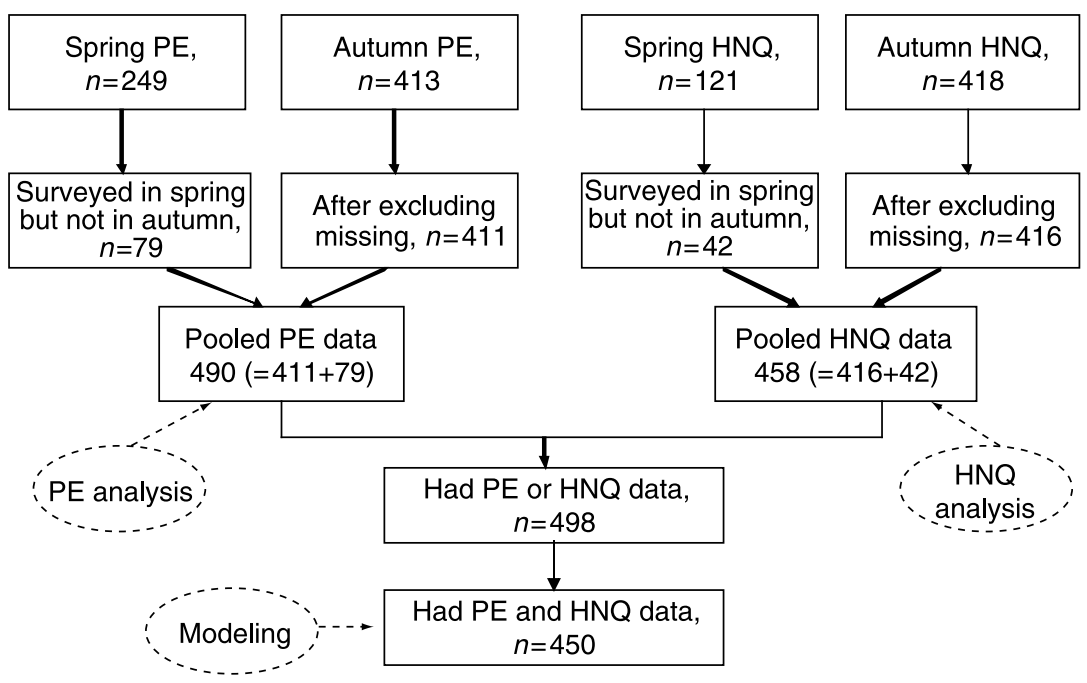

PE - physical examination, HNQT - Health and Nutrition Questionnaire. 